\title{
Meaning-making as a mediator of anxiety and depression reduction during cognitive behavioral therapy intervention in participants with adjustment disorders
}

\author{
José H. Marco ${ }^{1}$ @ | Sandra Alonso ${ }^{2,3}$ | Rosa Baños ${ }^{1,4}$
}

${ }^{1}$ Departamento de Personalidad, Evaluación y Tratamientos Psicológicos, Universitat de València, Valencia, Spain

${ }^{2}$ Catedra UMIVALE Innovación e Investigación en la Patologia del Trabajo, Valencia, Spain

${ }^{3}$ Escuela de Doctorado, Universidad Católica de Valencia, San Vicente Mártir, Valencia, Spain

${ }^{4}$ Ciber Fisiopatologia Obesidad y Nutrición (CB06/03), Instituto Salud Carlos III, Madrid, Spain

\section{Correspondence}

José H. Marco, Department of Personality, Evaluation and Psychological Treatment, University of Valencia, Avenida Blasco Ibañez, 21, Valencia CP 46010, Spain.

Email: jose.h.marco@uv.es

\begin{abstract}
There is a consensus among researchers about the link between low meaning in life and anxiety and depressive symptoms. One unanswered question is whether meaning-making is a mediator of the change in anxiety and depression symptoms in participants with adjustment disorders during cognitive behavioural therapy (CBT) treatment. The aims of this study were (a) to analyse whether there was meaningmaking during the application of the CBT, (b) to analyse whether meaning-making was a mediator of anxiety psychopathology and (c) to analyse whether meaningmaking was a mediator of depressive symptoms. The sample was composed of 115 patients who satisfied the full Diagnostic and Statistical Manual of Mental Disorders (DSM)-5 criteria for adjustment disorder as their primary diagnosis and completed CBT treatment in a primary care mental health service: $74.78 \%$ women, $n=86$, and $25.22 \%$ men, $n=29$, with a mean age of 41.89 (standard deviation $[S D]=10.39$ ) years. The diagnosis was established using the Structured Clinical Interview for DSM-5 (SCID-5), and participants filled out the Beck Anxiety Inventory, the Beck Depression Inventory and Purpose in Life questionnaires. The therapists were clinical psychologists with experience in clinical assessment. A repeated-measures analysis of variance (ANOVA) and two mediation analyses using the bootstrap method were performed. The results indicated that (a) There was meaning-making during the $\mathrm{CBT}$ because the treated sample showed a statistically significant improvement in meaning in life, and (b) meaning-making during the CBT was a partial mediator between anxiety symptoms and depressive symptoms before and after the treatment. The present study suggests that meaning in life could be an important variable in the psychopathology of adjustment disorders.
\end{abstract}

\section{KEYWORDS}

adjustment disorders, anxiety, depressive symptoms, meaning in life, meaning-making, mediation

\section{1 | INTRODUCTION}

Adjustment disorders have high societal costs for the people who experience them (Lépine, 2002), and they are highly prevalent. In general population-based studies, the prevalence rates were $2 \%$ (O'Donnell, Agathos, Metcalf, Gibson, \& Lau, 2019), and in studies with a Spanish sample in primary care, the prevalence was $2.94 \%$ (Fernandez et al., 2012). According to the Diagnostic and Statistical 
Manual of Mental Disorders (DSM-5; American Psychiatric Association (APA), 2013), adjustment disorders are defined as an abnormal stress response to an identifiable stressful life event or life change (occurring within 3 months of the onset of the stressor), characterized by behavioural symptoms, symptoms of preoccupation, excessive worry, anxiety, recurrent and distressing thoughts about the stressor or constant rumination about its implications. Moreover, the marked distress is out of proportion with the severity of the stressor. These clinically significant symptoms are a consequence of a failure to adapt, and they produce clinical interference in everyday life (e.g., difficulties concentrating or sleep disturbance and severe depressive symptoms; Casey, Jabbar, O'Leary, \& Doherty, 2015). Moreover, the symptoms do not represent normal bereavement, and the stress-related symptoms do not meet the criteria for another mental disorder (APA, 2013). The DSM-5 (APA, 2013) indicates six subtypes: with depressed mood, with anxiety, with anxiety and depressed mood, with conduct disturbance, with mixed disturbance of emotions and conduct and unspecified.

The diagnostic criteria for adjustment disorders have been a source of controversy in terms of their validity and reliability (Patra \& Sarkar, 2013). Adjustment disorders make up a diagnosis that arises between a normal response to stress and mental disorders. They are subthreshold entities that overlap with other diagnoses and are defined ambiguously (Strain \& Diefenbacher, 2008). For example, the criterion $\mathrm{E}$ for adjustment disorder involves spontaneous recovery or a good outcome because it states that 'once the stressor has terminated, the symptoms do not persist for more than an additional six months' (APA, 2013). Thus, they are mental disorders with spontaneous recovery by definition.

However, several studies have found that symptoms may increase over time and develop into a severe disorder (O'Donnell et al., 2019). In some patients, the adjustment disorders are potentially serious and can present with life-threatening features, showing a high prevalence of non-suicidal self-injuries and suicidal behaviours (Casey et al., 2015). Participants with adjustment disorders can show loss of interest in work, social life and leisure activities.

Frankl (2006) defines meaning in life as the experience of freedom, responsibility and self-determination, and he associates it with a positive view of life, the future and oneself. Martela and Steger (2016) suggest that meaning in life is composed of three dimensions: (a) coherence, the cognitive component of meaning in life, is defined as the degree to which people feel that the world around them is structured, predictable and explainable; (b) purpose, the motivational dimension, refers to the way people experience their life as guided by valuable life goals and (c) significance, the affective component, refers to the sense of the inherent value of life and implies having a life worth living. Thus, high levels of meaning in life contribute to proposing and achieving vital goals that direct and grant significance to one's life (Zika \& Chamberlain, 1992).

There is a broad consensus among researchers about the link between low meaning in life and anxiety psychopathology and depressive symptoms (Harlow, Newcomb, \& Bentler, 1986; Marco, Pérez, \& García-Alandete, 2016; Schulenberg, Strack, \&

\section{Key Practitioner Messages}

- The results of this study suggest that there was meaningmaking during the CBT.

- The results of this study suggest that meaning-making during the CBT was a significant mediator between anxiety symptoms before and after the treatment.

- The results of this study suggest that meaning-making during the CBT was a significant mediator between depression symptoms before and after the treatment.

- Our results suggest the need to assess meaning in life in participants with adjustment disorders.

Buchanan, 2011; Volkert, Schulz, Brütt, \& Andreas, 2014) and suicidality (Costanza, Prelati, \& Pompili, 2019). In this regard, the negative association between meaning in life and anxiety symptoms has been clearly established in several studies (e.g., Park \& Baumeister, 2017; Steger, Mann, Michels, \& Cooper, 2009). High meaning in life has been associated with lower stress reactions, whereas perceiving life as meaningless has been shown to increase vulnerability to stress (Steger, Kashdan, Sullivan, \& Lorentz, 2008).

In the context of trauma and stress-related disorders, Park and Folkman (1997) introduced the meaning-making model, which proposes that people continuously search for and assign meanings to their behaviours, relationships, situations, values, goals and events. Thus, after the occurrence of a stressful event, people begin a set of processes that include searching for and assigning meaning to the event (situational meaning). If the situational meaning of the event violates or contradicts their global meaning, values or purpose, they will experience distress, which will lead to efforts to reduce these discrepancies through meaning-making processes (e.g. continuous search for meaning). Perceptions of discrepancy (e.g., with the individual's sense of control) are thought to create the distress that drives meaning-making efforts (Joseph \& Linley, 2005). In this direction, several studies have found that meaning-making is an effective coping strategy for dealing with stressors and an adaptive response to the occurrence of negative and traumatic events (e.g., Davis, Wortman, Lehman, \& Silver, 2000; Janoff-Bulman, 2004; Park \& Baumeister, 2017; Updegraff, Silver, \& Holman, 2008). Moreover, review studies on therapy focused on improving meaning in life found that the enhancement of meaning in life while coping with disease was associated with an improvement in anxiety symptoms in people with cancer (Guerrero-Torrelles, Monforte-Royo, Rodríguez-Prat, Porta-Sales, \& Balaguer, 2017).

However, in other studies on meaning-making and psychological adjustment, the results have been contradictory. Kernan and Lepore (2009) found that the meaning-making process was associated with more negative emotions, suggesting that it is a distressing psychological state. Bonanno, Wortman, and Nesse (2004) found that the meaning-making processes predicted poorer subsequent adjustment 
to the loss. Davis and Morgan (2008) found that, in participants with tinnitus, meaning-making was associated with positive changes in life goals and philosophy of life. They did not, however, report higher well-being or fewer depression symptoms than those without meaning-making.

Ruminating and excessive worry are common characteristics of participants with adjustment disorders (APA, 2013). The purpose and results of the rumination or worry depend on each patient. For some patients, rumination and worry could be cognitive processing aimed at finding some meaning in the resolution to the stressor and achieve better adaptation. However, other patients could perceive it as intrusive thoughts that cause more interference and make it difficult to adapt to the stressor (Nolen-Hoeksema \& Larson, 1999). In a study on rumination and bereavement, Michael and Snyder (2005) found that meaning-making was negatively correlated with rumination $(r=-.66)$.

Studies with participants with bereavement (Bower, Kemeny, Taylor, \& Fahey, 1998) or trauma (Silver, Boon, \& Stones, 1983) found that when continuous cognitive processing was capable of meaningmaking, it led to developing better adjustment, but if it did not produce meaning-making, it led to worse coping and adjustment. Thus, these studies suggest that the reduction in rumination and excessive worry could depend on the participants' meaning-making processes after the stressful event. However, research on meaning life in participants with adjustment disorders is scarce.

Meaning-making is a different construct from resilience, but closely related to it. Resilience is a process of 'bouncing back' from difficult experiences and adapting well in the face of adversity, trauma, tragedy, threats or significant sources of stress (Joyce et al., 2018), and meaning-making in negative experiences has been found to be a coping skill and provides a foundation for resilience to high stressors (Kashdan \& McKnight, 2009; King, Hicks, Krull, \& Del Gaiso, 2006). In longitudinal studies, the sense of coherence has been found to be a significant predictor of resilience when facing stressful life situations (e.g., war victims). The sense of coherence is one of the three dimensions of meaning of life, and so these studies suggest that resilience is a more general construct than meaning-making, although they are associated (Eshel, Kimhi, Lahad, \& Leykin, 2017). In the same way, according to the meaning-making model, global meaning would be made up of general schemas, beliefs and values. The values and the behaviours related to values are the motivational dimension of meaning, called purpose (Martela \& Steger, 2016). Thus, when the stressful event violates individuals' values, people will begin meaning-making processes, which include searching for and assigning meaning to the event and to the actions related to values (situational meaning; Park, 2010).

To the data, one unanswered question is whether meaningmaking is a mediator of the change in anxiety and depression symptoms. Park (2010) suggested that to answer the question of whether meaning-making produces better psychological adjustment by reducing anxiety and depression, longitudinal studies are necessary, with meaning-making as a mediating factor between anxiety and depression psychopathology.
Despite the relevance of adjustment disorders, evidence about effective psychotherapy is scarce, and there is currently no gold standard treatment approach for participants with adjustment disorders. Cognitive behavioural therapy (CBT) is one of the few psychotherapies that has already provided efficacy results in the treatment of adjustment disorders (Currier, Holland, \& Neimeyer, 2010; Eimontas, Rimsaite, Gegieckaite, Zelviene, \& Kazlauskas, 2018). CBT had a high effect on reducing anxiety and depressive psychopathology, and it has been associated with sustained maintenance of improvements after treatment for adjustment disorders (Quero et al., 2019).

Based on the meaning-making model, it is reasonable to suggest that during treatment with $\mathrm{CBT}$, patients will practice meaning-making. CBT focuses on making the patient's schemas, irrational beliefs and core beliefs more flexible (Szentagotai, David, Lupu, \& Cosman, 2008). This flexibility could enhance the assimilation and accommodation processes that are necessary for the construction of meaning in life (Steger, 2012). Moreover, with the skills learned through CBT, the participants will improve their understanding of stressful events, integrate them into their global schemes and reorient their values and behaviours, which will lead to meaningmaking and reduce anxiety and depression symptoms after the treatment. By contrast, following the meaning-making model, if patients do not improve meaning during CBT, they will not experience a reduction in symptoms after the treatment. Thus, testing whether meaning-making is a mediator of anxiety and depression symptoms during CBT treatment could help us to improve the current treatments for adjustment disorders.

The aims of the present research are (a) to analyse whether there is meaning-making during the application of the CBT, (b) to analyse whether meaning-making is a mediator of anxiety psychopathology and (c) to analyse whether meaning-making is a mediator of depressive symptoms.

Taking into account the previously mentioned literature, we hypothesize that (a) after the treatment with $\mathrm{CBT}$, there is meaningmaking; (b) meaning-making mediates the association between anxiety symptoms before and after the treatment and (c) meaning-making mediates the association between depressive symptoms before and after the treatment.

\section{2 | METHOD}

\section{1 | Participants}

Participants were 115 patients who were part of the sample of a multisite clinical trial at eight Mental Health Services in different cities in Spain. The inclusion criteria included (a) patients who satisfied the full DSM-5 (APA, 2013) criteria for adjustment disorder as their primary diagnosis and (b) participants who completed CBT treatment in a primary care mental health service. The exclusion criteria included (a) moderate or severe intellectual disability and (b) a diagnosis of schizophrenia, bipolar disorder, severe personality disorders, 
organic mental disorders, substance use disorders or major depressive disorder. All the participants were Caucasian. The clinical sample comprised $74.78 \%$ women, $n=86$, and $25.22 \%$ men, $n=29$. The participants' ages ranged from 20 to 60 years, with a mean of 41.89 (standard deviation $[S D]=10.39$ ); $34.79 \%, n=40$, had primary school level studies, $41.74 \%, n=48$, had a high school education and $23.47 \%, n=27$, had university level studies. Regarding the DSM-5 subtypes (APA, 2013): $50.4 \%, n=58$, had anxiety and depressed mood 309.28 (F43.23); 20.8\%, $n=24$, had anxiety 309.24 (F43.22); 3.47\%, $n=4$, had depressed mood 309.0 (F43.21); 2.6\%, $n=3$, had conduct disturbance 309.3 (F43.24) and 22.73\%, $n=26$, had unspecific 309.9 (F43.20).

Participants were volunteers who did not receive any compensation for their participation, and they signed an informed consent form. Ethical approval for carrying out this study was granted by the Autonomic Ethics Committee of Clinical Studies. The data used to address the aims of this study were drawn from a larger study about early intervention with CBT in people with adjustment disorders (Marco, Alonso, \& Andani, 2018).

\subsection{Assessments and measures}

Structured Clinical Interview for DSM-5 disorders-Clinician version (SCID-5-CV; First, Williams, Karg, \& Spitzer, 2015). This is an interview for making the major DSM-5 (APA, 2013) diagnoses.

Purpose in Life (PIL; Crumbaugh \& Maholick, 1969) This is a 20-item Likert scale with seven response levels (from 1 to 7) related to different aspects of MIL (e.g., enthusiasm vs. boredom, excitement about living, presence of clear life goals, wishing for more lives, good things in life, having a reason to be alive, capacity to find meaning, presence of goals/life purpose). The total score ranges from 20 to 140 , so that higher scores indicate greater meaning in life. We utilized the Spanish version (Noblejas de la Flor, 2000). In our sample, excellent internal consistency was found for the PIL $(\alpha=.91)$. To evaluate meaning-making, we calculated the increase in the PIL scores during the treatment.

Beck Anxiety Inventory (BAI; Beck \& Steer, 1993). We utilized the Spanish adaptation of the BAI (Sanz \& Navarro, 2003). This inventory consists of 21 items rated on a Likert scale with four response options (from 0 to 3 ), and it assesses anxiety symptoms. It establishes different quantitative ranges of anxiety: absent or minimal anxiety $(<7)$, mild anxiety (8-15), moderate anxiety (16-25) and severe anxiety (>26). The total score ranges from 0 to 63 , with higher scores indicating greater anxiety symptoms. Excellent internal consistency was found $(\alpha=.91)$ in our sample.

Beck Depression Inventory-II (BDI-II; Beck, Steer, \& Brown, 1996). This inventory is composed of 21 items with four response options (0-4), and it assesses depressive symptomatology. It establishes different quantitative ranges of depression: absent or minimal depression (<13), mild to moderate depression (14-19), moderate depression (20-28) and severe depression (>28). It offers good psychometric properties in its Spanish version (Sanz, García-Vera,
Espinosa, Fortun, \& Vazquez, 2005). It showed adequate reliability $(\alpha=0.93)$ in our sample.

\section{3 | Procedure}

In the first session before the treatment, the diagnosis was established using the SCID-5 (First et al., 2015), and at the beginning and end of the treatment, participants filled out the BAI, BDI and PIL. All the interviewers were $\mathrm{PhD}$ and clinical Psychologists with experience in clinical assessment. The therapists were blind to the research hypothesis.

The psychotherapy treatment was a standardized application of CBT. The main modules of the CBT included explaining the importance of emotions, irrational beliefs and the role of negative thoughts in the appearance of anxiety disorders; cognitive restructuring techniques; elimination of avoidance behaviours; exposure to feared situations and relapse prevention (Currier et al., 2010). The manualized protocol includes homework the patients completed during the week after each session. These homework activities were (a) reading a brief manual about the therapeutic contents; (b) filling in self-registers about situations, thoughts and emotions that cause discomfort and (c) fill in self-registers containing exercises to practice the contents of the treatment sessions. Before starting the next psychotherapy session, the psychologist checked that the participants had completed the homework and adhered to the treatment. The CBT was applied by psychologists who were experts in CBT for anxiety disorders and had more than 10 years of experience. The participants received an average of 9.1 (4.01) sessions of individual CBT psychotherapy. The study had the approval of the Ethics Committee on Clinical Studies.

\subsection{1 | Statistical procedure}

First, to calculate the efficacy of CBT in improving meaning in life, anxiety symptomatology and depression in the participants, a repeated-measures analysis of variance (ANOVA) was performed. To calculate meaning-making (the change produced in meaning in life) during the CBT, we created a new variable called MIL T1-T2, by subtracting the scores obtained before beginning the treatment from the scores obtained at the end of treatment. Then, two mediation analyses were carried out, taking the scores on the BDI and BAI before treatment as predictor variables, meaning-making (MIL T1-T2) during $\mathrm{CBT}$ as the mediator variable and the scores on the BDI and BAI after treatment as outcome variables. In order to test the potential mediator effect, we used the bootstrap method (10,000 replications) and calculated the total, direct and indirect effects, obtaining the variance explained ( $R^{2}$ adjusted) by the mediation. The calculations and the mediation model were performed with the JASP statistical program (JASP Team, 2019). The variables were mean-centred prior to analysis. Variance inflation factors (VIF) were calculated for the predictors in the multiple regression, and none of them was higher than 10 , thus showing no multicollinearity problems (Stevens, 2007). 


\section{3 | RESULTS}

As Table 1 shows, after the CBT for adjustment disorders, the sample showed a statistically significant improvement in meaning in life (PIL; $F_{(1,163)}=387.63, p<0.0001, \eta^{2}=.74$ ), anxiety symptoms (BAl; $\left.F_{(1,163)}=427.62, p<0.0001, \eta^{2}=.75\right)$ and depression symptoms $\left(\mathrm{BDI} ; F_{(1,163)}=297.91, p<0.0001, \eta^{2}=.78\right)$.

As Table 2 shows, meaning-making during the CBT (PIL T1-T2) was a partial mediator between anxiety symptoms before and after the treatment $\left(R^{2}=.26, z=2.859, p<.001\right.$ [0.057, 0.306 \{95\%\}]; see Figure 1). Finally, as Table 3 shows, meaning-making during the CBT (PIL T1-T2) was a partial mediator between depressive symptoms before and after the treatment $\left(R^{2}=.47, z=4.079, p<.001[0.126\right.$, 0.360 \{95\%\}]; see Figure 2).

TABLE 1 Pretreatment and posttreatment scores of participants

\begin{tabular}{|c|c|c|c|c|c|}
\hline & Pretreatment T1 & Posttreatment T2 & & & \\
\hline & $M(S D)$ & $M(S D)$ & $F_{(1,162)}$ & $p$ & $\eta^{2}$ \\
\hline Meaning in Life (PIL) & $79.38(19.26)$ & $109.43(14.65)$ & 387.63 & .0001 & .74 \\
\hline Beck Anxiety Inventory & 29.78 (11.97) & $9.04(7.88)$ & 427.62 & .0001 & .75 \\
\hline Beck Depression Inventory & 30.78 (10.87) & $8.62(6.67)$ & 297.91 & .0001 & .80 \\
\hline
\end{tabular}

Abbreviations: PIL, Purpose In Life; SD, standard deviation.

TAB LE 2 Model of mediation of meaning-making between anxiety symptoms (BAI) before and after CBT

\begin{tabular}{|c|c|c|c|c|c|c|c|}
\hline & Coefficient & Error standard & $z$ value & $p$ & \multicolumn{2}{|c|}{ Confidence interval (95\%) } & Variance explained \\
\hline Total effects & 0.181 & 0.063 & 2.859 & $<.001$ & 0.057 & 0.306 & \\
\hline Indirect effects & -0.091 & 0.034 & -2.676 & $<.001$ & -0.158 & -0.024 & $26 \%$ \\
\hline
\end{tabular}

Abbreviations: BDI, Beck Anxiety Inventory; CBT, cognitive behavioural therapy.

FIGURE 1 The meaningmaking (PIL T1-T2) during cognitive behavioural therapy (CBT) as mediator of change anxiety symptoms before and after treatment. Note: PrBAI, Pretreatment Beck Anxiety Inventory; PtBDI, Posttreatment Beck Anxiety Inventory; PIL, Purpose in Life Test change during CBT

\section{4 | DISCUSSION}

The aims of the present research were (a) to analyse whether there was meaning-making during the application of the CBT, (b) to analyse whether meaning-making was a mediator of anxiety psychopathology and (c) to analyse whether meaning-making was a mediator of depressive symptoms.

Regarding our first aim, we found that during the CBT treatment meaning in life increased significantly, thus there was meaning-making in participants with adjustment disorders. These results are consistent with other studies that found improvements in meaning in life during psychotherapy. Waisberg and Porter (1994), after a multicomponent intervention for people with substance abuse (alcohol), found that meaning in life increased, reaching the

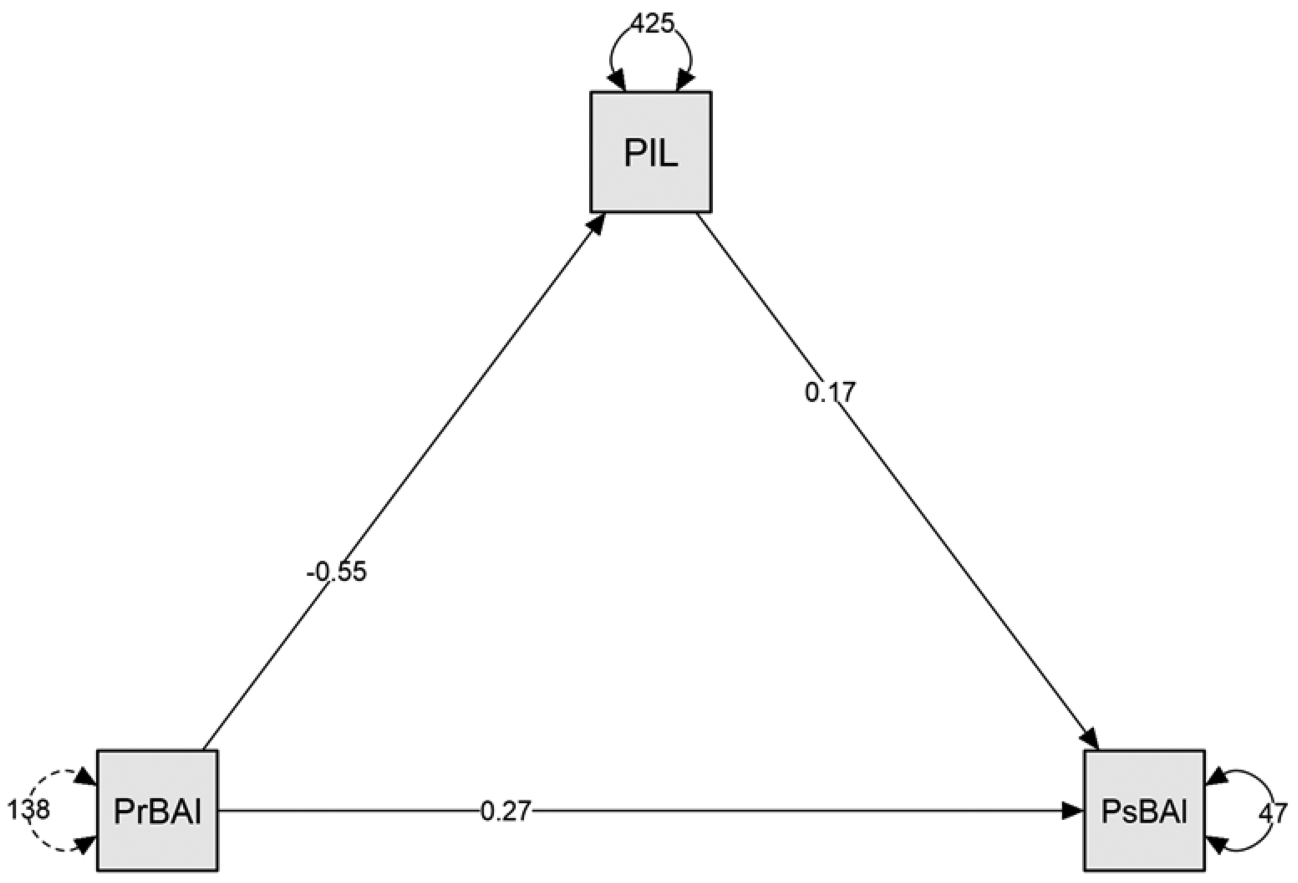


TAB LE 3 Model of mediation of meaning-making between depressive symptoms (BDI) before and after CBT

\begin{tabular}{|c|c|c|c|c|c|c|c|}
\hline & Coefficient & Error standard & $z$ value & $p$ & \multicolumn{2}{|c|}{ Confidence interval (95\%) } & Variance explained \\
\hline Total effects & 0.243 & 0.060 & 4.079 & $<.001$ & 0.126 & 0.360 & \\
\hline Direct effects & 0.406 & 0.051 & 7.905 & $<.001$ & 0.305 & 0.506 & \\
\hline Indirect effects & -0.162 & 0.043 & -3.807 & $<.001$ & -0.246 & -0.079 & $47 \%$ \\
\hline
\end{tabular}

Abbreviations: BDI, Beck Depression Inventory; CBT, cognitive behavioural therapy.

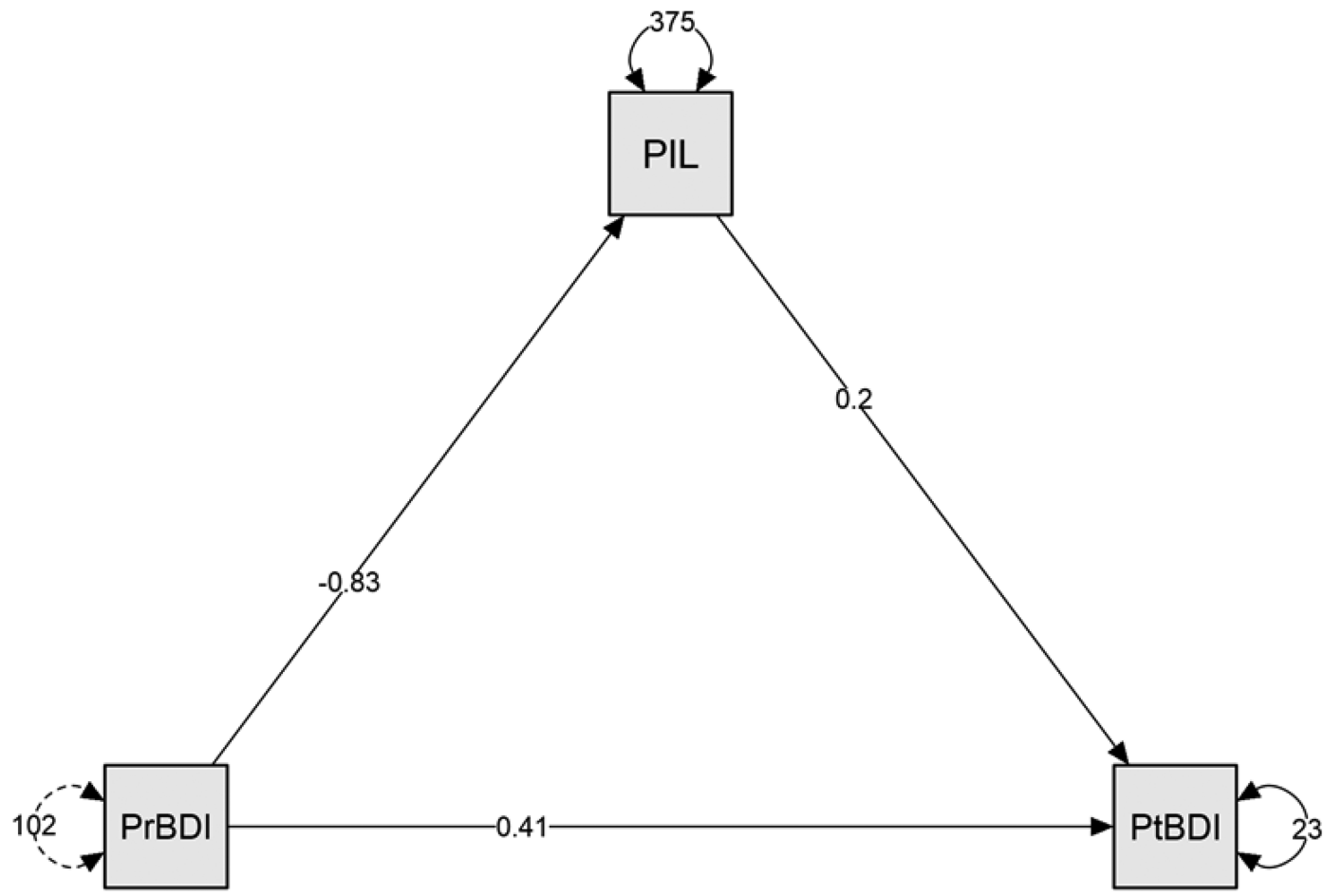

FIGURE 2 The meaning-making (PIL T1-T2) during cognitive behavioural therapy (CBT) as mediator of change in depression symptoms before and after treatment. Note: PrBDI, Pretreatment Beck Depression Inventory; PtBDI, Posttreatment Beck Depression Inventory; PIL, Purpose in Life change during CBT

same level as the general population. In addition, in a psychodynamic psychotherapy for people with depressive, anxiety and somatoform disorders, Volkert et al. (2014) found that meaning in life improved at the end of the therapy and at follow-up. However, none of these previous studies used a standard CBT intervention. Thus, as far as we know, this is the first study to show that standard CBT can facilitate meaning-making in participants with adjustment disorders.

Regarding the second aim, the meaning-making during CBT was a partial mediator of the improvement in anxiety psychopathology during the treatment. Our results coincide with other previous studies showing a strong negative association between meaning in life and anxiety (Park \& Baumeister, 2017). These results are congruent with other findings showing that meaning in life facilitated adaptation to acute stressors (Updegraff et al., 2008) and with studies suggesting that constructing meaningful interpretations is an effective strategy for coping with and adapting to stressors and anxiety (Davis et al., 2000; Park \& Baumeister, 2017).
With regard to our third aim, the meaning-making during CBT was a partial mediator of the improvement in depressive symptoms during the treatment. These results support previous cross-sectional studies indicating that high meaning in life is negatively associated with negative affect (e.g., King et al., 2006). In this regard, meaning in life was found to be highly and negatively associated with depression (Heisel \& Flett, 2004; Mascaro \& Rosen, 2005). Moreover, longitudinal studies showed that meaning in life was a variable that predicted and moderated depression. For example, Disabato, Kashdan, Short, and Jarden (2017) found that higher levels of meaning in life predicted decreased levels of depression after 3 and 6 months in nonclinical adults. Marco, Cañabate, Llorca, and Pérez (2020), in a study with a clinical sample, found that meaning in life moderated the association between suicide ideation at baseline and at the 7-month follow-up and that meaning in life moderated the association between hopelessness at baseline and at the 7-month follow-up. Thus, meaning in life was a moderator and independent variable from hopelessness and suicidal ideation (both are core symptoms of depression). 
Our results can be explained from the perspective of the meaning-making model, which suggests that after the occurrence of a stressful event, individuals appraise and assign meaning to the event. The extent to which the situational meaning is discrepant with their global meaning determines the extent to which they experience distress, and when people make a new situational meaning that is congruent with their global meaning, the distress is reduced (Park, 2010). This model suggests that psychotherapy facilitates the process of assimilating the situational meaning and accommodating the schemes that make up the global meaning.

From the CBT perspective, meaning-making is seen as a cognitive process that leads to the development of a rational vision of the self, others and the world. With the help of psychotherapy, clients learn to identify the meaning they give to their thoughts and beliefs, and through cognitive skills, this meaning is modified (Szentagotai et al., 2008). Thus, the dimension of coherence would be increased through the therapeutic process. Future research could study whether this dimension of meaning would be a catalyst for change in the other dimension of meaning, purpose and significance. Thus, CBT implicitly involves meaning-making.

However, we can highlight that other possible explanations for the improvement in depression and anxiety after CBT are possible, apart from meaning-making. First, spontaneous recovery seems to be rather normal in adjustment disorders, and so the reduction in symptoms may not be a result of psychotherapy (because we do not have a control group, spontaneous recovery was not controlled). Second, CBT is an effective treatment to reduce rumination, worry, anxiety and depression symptoms (Teismann et al., 2014). Although we previously mentioned that rumination, anxiety and depressive symptoms were negatively associated with the construction of meaning (Michael \& Snyder, 2005), it is possible that the reductions in rumination, anxiety and depressive symptoms were produced by the CBT, and this symptom reduction leads to better understanding, coherence of the event and better meaning-making. Thus, the association between CBT, meaning in life, depression and anxiety symptoms could be explained by other variables that might affect the results (e.g., rumination, positive affect and symptom reduction).

Our study presents other limitations that must be taken into account when interpreting the results. The first limitation is that there was no control group, and so it is not possible to conclude that CBT is effective for meaning-making. The second limitation is that to evaluate the variables we have used self-report measures alone, and selfreports may not reflect the real constructs (e.g., meaning-making). Therefore, future research should evaluate the meaning-making construct through interviews. The third limitation is that the entire sample was from Spain, and in other countries or cultures, the construct of meaning in life could have a different role as a predictor variable. Therefore, it is necessary to replicate the present study using a crosscultural design with samples from other countries such as the United States and African or Asian countries. Another limitation is that we cannot ensure that the absence of meaning-making is an independent factor from anxiety or depression. Although in our study, we rule out multicollinearity between the variables, it is possible that absence of meaning-making could represent another part of anxiety and depressive symptoms and not an independent factor that influences them. Previous authors (e.g., Frankl, 1984) suggested that existential depression, as a subtype of depression, was characterized by absence of meaning in life (Addis \& Jacobson, 1996). Thus, future research should analyse whether the absence of meaning of life is a construct that is part of depression/anxiety or an independent construct. Another limitation is that participants with a diagnosis of schizophrenia, bipolar disorder, severe personality disorders organic mental disorders, substance use disorders or major depressive disorder were excluded from the study. Thus, our results are only generalizable to patients who satisfy the full DSM-5 criteria for adjustment disorder as their primary diagnosis without comorbidity. Future research is necessary to confirm our results in a sample composed of participants diagnosed with adjustment disorders with psychiatric comorbidity. These limitations should always be taken into consideration when generalizing the results, which should be considered exploratory.

The results of our study could have practical implications for the prevention of adjustment disorders. They support the need to assess meaning in life in participants with adjustment disorders. Finally, encouraging the development of meaning in life in non-clinical participants (e g., adolescents) could be a strategy for increasing resilience and preventing adjustment and anxiety disorders (Burrow \& Hill, 2011; Kim, Lee, Yu, Lee, \& Puig, 2005).

A question that is still not resolved is whether we could improve the treatments for adjustment disorders if we focus some sessions of CBT on the construction of a meaningful life. Therefore, future studies should analyse, with a randomize control trial, whether adding a specific treatment component focused on meaning in life to CBT could increase the efficacy of CBT for adjustment disorders (e.g., Wong, 1999) with these relevant variables controlled.

One of the strengths of this study is the sample used, which comes from several cities in Spain. Hence, it is safe to state that the sample is representative of Spanish patients seen in daily clinical practice and that these results may be generalizable to other populations of participants with adjustment disorders.

In conclusion, based in the results of the study, we propose that meaning in life could be an important variable in the psychopathology of adjustment disorders.

\section{DATA AVAILABLE STATEMENT}

The data that support the findings of this study are available on request from the corresponding author. The data are not publicly available due to privacy or ethical restrictions.

\section{ORCID}

José H. Marco (D) https://orcid.org/0000-0002-1545-6452

\section{REFERENCES}

Addis, M. E., \& Jacobson, N. S. (1996). Reasons for depression and the process and outcome of cognitive-behavioral psychotherapies. Journal of 
Consulting and Clinical Psychology, 64(6), 1417-1424. https://doi.org/ 10.1037/0022-006X.64.6.1417

American Psychiatric Association (APA). (2013). Diagnostic and statistical manual of mental disorders (5th ed.). Washington, DC: Author.

Beck, A. T., \& Steer, R. A. (1993). Manual for the Beck Anxiety Inventory. San Antonio, TX: Psychological Corporation.

Beck, A. T., Steer, R. A., \& Brown, G. K. (1996). Manual for the Beck Depression Inventory-II (2nd ed.). San Antonio: Psychological Corporation.

Bonanno, G. A., Wortman, C. B., \& Nesse, R. M. (2004). Prospective patterns of resilience and maladjustment during widowhood. Psychology and Aging, 19, 260-271. https://doi.org/10.1037/0882-7974.19. 2.260

Bower, J. E., Kemeny, M. E., Taylor, S. E., \& Fahey, J. L. (1998). Cognitive processing, discovery of meaning, CD4 decline, and AIDS-related mortality among bereaved HIV-seropositive men. Journal of Consulting and Clinical Psychology, 66, 979-986. https://doi.org/10.1037/0022-006X. 66.6.979

Burrow, A. L., \& Hill, P. L. (2011). Purpose as a form of identity capital for positive youth adjustment. Developmental Psychology, 47(4), 1196-1206. https://doi.org/10.1037/a0023818

Casey, P., Jabbar, F., O'Leary, E., \& Doherty, A. M. (2015). Suicidal behaviours in adjustment disorder and depressive episode. Journal of Affective Disorders, 174, 441-446. https://doi.org/10.1016/j.jad.2014. 12.003

Costanza, A., Prelati, M., \& Pompili, M. (2019). The meaning in life in suicidal patients: The presence and the search for constructs. A systematic review. Medicina, 55(8), 465. https://doi.org/10.3390/ medicina55080465

Crumbaugh, J. C., \& Maholick, L. T. (1969). Manual of instructions for the purpose in life test. Saratoga: Viktor Frankl Institute of logotherapy.

Currier, J. M., Holland, J. M., \& Neimeyer, R. A. (2010). Do CBT-based interventions alleviate distress following bereavement? A review of the current evidence. International Journal of Cognitive Therapy, 3(1), 77-93. https://doi.org/10.1521/ijct.2010.3.1.77

Davis, C. G., \& Morgan, M. S. (2008). Finding meaning, perceiving growth, and acceptance of tinnitus. Rehabilitation Psychology, 53(2), 128-138. https://doi.org/10.1037/0090-5550.53.2.128

Davis, C. G., Wortman, C. B., Lehman, D. R., \& Silver, R. C. (2000). Searching for meaning in loss: Are clinical assumptions correct? Death Studies, 24, 497-540. https://doi.org/10.1080/07481180050121471

Disabato, D. J., Kashdan, T. B., Short, J. L., \& Jarden, A. (2017). What predicts positive life events that influence the course of depression? A longitudinal examination of gratitude and meaning in life. Cognitive Therapy and Research, 41(3), 444-458. https://doi.org/10.1007/ s10608-016-9785-x

Eimontas, J., Rimsaite, Z., Gegieckaite, G., Zelviene, P., \& Kazlauskas, E. (2018). Internet-based self-help intervention for ICD-11 adjustment disorder: Preliminary findings. Psychiatric Quarterly, 89(2), 451-460. https://doi.org/10.1007/s11126-017-9547-2

Eshel Y., Kimhi S., Lahad M., \& Leykin D. (2017). Individual attributes as predictors of protective and risk components of resilience under continuing terror attacks: A longitudinal study. Personality and Individual Differences, 114, 160-166. https://doi.org/10.1016/j.paid.2017. 03.033

Fernández, A., Mendive, J. M., Salvador-Carulla, L., Rubio-Valera, M., Luciano, J. V., Pinto-Meza, A., ... Serrano-Blanco, A. (2012). Adjustment disorders in primary care: Prevalence, recognition and use of services. The British Journal of Psychiatry, 201(2), 137-142. https://doi. org/10.1192/bjp.bp.111.096305

First, M. B., Williams, J. B. W., Karg, R. S., \& Spitzer, R. L. (2015). Structured clinical interview for DSM-5 disorders-Clinician version (SCID-5-CV).

Frankl, V. E. (1984). Man's search for meaning (3rd ed.). New York: First Washington Square Press. (Original work published 1963)

Frankl, V. E. (2006). The unheard cry for meaning. Psychotherapy and humanism. Boston, MA: Beacon Press.
Guerrero-Torrelles, M., Monforte-Royo, C., Rodríguez-Prat, A., PortaSales, J., \& Balaguer, A. (2017). Understanding meaning in life interventions in patients with advanced disease: A systematic review and realist synthesis. Palliative Medicine, 31(9), 798-813. https://doi.org/10. 1177/0269216316685235

Harlow, L. L., Newcomb, M. D., \& Bentler, P. M. (1986). Depression, selfderogation, substance use, and suicide ideation: Lack of purpose in life as a mediational factor. Journal of Clinical Psychology, 42(1), 5-21. https://doi.org/10.1002/1097-4679(198601)42:1<5:AIDJCLP2270420102>3.0.CO;2-9

Heisel, M. J., \& Flett, G. L. (2004). Purpose in life, satisfaction with life, and suicide ideation in a clinical sample. Journal of Psychopathology and Behavioral Assessment, 26, 127-135. https://doi.org/10.1023/B:JOBA. 0000013660.22413.e0

Janoff-Bulman, R. (2004). Posttraumatic growth: Three explanatory models. Psychological Inquiry, 15(1), 30-34.

JASP Team. (2019). JASP (Version 0.11.1) [Computer software].

Joseph, S., \& Linley, P. A. (2005). Positive adjustment to threatening events: An organismic valuing theory of growth through adversity. Review of General Psychology, 9, 262-280. https://doi.org/10.1037/ 1089-2680.9.3.262

Joyce S., Shand F., Tighe J., Laurent S. J., Bryant R. A., \& Harvey S. B. (2018). Road to resilience: A systematic review and meta-analysis of resilience training programmes and interventions. BMJ Open, 8(6), e017858. https://doi.org/10.1136/bmjopen-2017-017858

Kashdan, T. B., \& McKnight, P. E. (2009). Origins of purpose in life: Refining our understanding of a life well lived. Psihologijske teme, 18(2), 303-313.

Kernan, W. D., \& Lepore, S. J. (2009). Searching for and making meaning after breast cancer: Prevalence, patterns, and negative affect. Social Science \& Medicine, 68, 1176-1182. https://doi.org/10.1016/j. socscimed.2008.12.038

Kim, T. H., Lee, S. M., Yu, K., Lee, S., \& Puig, A. (2005). Hope and the meaning of life as influences on Korean adolescents' resilience: Implications for counselors. Asia Pacific Education Review, 6(2), 143-152. https:// doi.org/10.1007/BF03026782

King L. A., Hicks J. A., Krull J. L., \& Del Gaiso A. K. (2006). Positive affect and the experience of meaning in life. Journal of Personality and Social Psychology, 90(1), 179-196. https://doi.org/10.1037/0022-3514.90. 1.179

Lépine, J.-P. (2002). The epidemiology of anxiety disorders: Prevalence and societal costs. The Journal of Clinical Psychiatry, 63(14), 4-8.

Marco, J. H., Alonso, S., \& Andani, J. (2018). Early intervention with cognitive behavioral therapy reduces sick leave duration in people with adjustment, anxiety and depressive disorders. Journal of Mental Health, 27, 1-9. https://doi.org/10.1080/09638237.2018.1521937

Marco, J. H., Cañabate, M., Llorca, G., \& Pérez, S. (2020). Meaning in life moderates hopelessness, suicide ideation,and borderline psychopathology in participants with eating disorders: A longitudinal study. Clinical Psychology \& Psychotherapy, 27, 146-158. https://doi.org/10. 1002/cpp.2414

Marco, J. H., Pérez, S., \& García-Alandete, J. (2016). Meaning in Life buffers the association between risk factors for suicide and hopelessness in participants with mental disorders. Journal of Clinical Psychology, 72, 689-700. https://doi.org/10.1002/jclp.22285

Martela, F., \& Steger, M. F. (2016). The three meanings of meaning in life: Distinguishing coherence, purpose, and significance. The Journal of Positive Psychology, 11(5), 531-545. https://doi.org/10.1080/ 17439760.2015.1137623

Mascaro, N., \& Rosen, D. H. (2005). Existential meaning's role in the enhancement of hope and prevention of depressive symptoms. Journal of Personality, 73, 985-1014. https://doi.org/10.1111/j.1467-6494. 2005.00336.x

Michael, S. T., \& Snyder, C. R. (2005). Getting unstuck: The roles of hope, finding meaning, and rumination in the adjustment to bereavement 
among college students. Death Studies, 29(5), 435-458. https://doi. org/10.1080/07481180590932544

Noblejas de la Flor, M. A. (2000). Fiabilidad de los tests PIL y Logotest. NOUS. Boletín de Logoterapia y Análisis Existencial, 4, 81-90.

Nolen-Hoeksema, S., \& Larson, J. (1999). Coping with loss. Mahwah, NJ: Lawrence Erlbaum Associates.

O'Donnell, M. L., Agathos, J. A., Metcalf, O., Gibson, K., \& Lau, W. (2019). Adjustment disorder: Current developments and future directions. International Journal of Environmental Research and Public Health, 16 (14), 2537. https://doi.org/10.3390/ijerph16142537

Park, C. L. (2010). Making sense of the meaning literature: An integrative review of meaning making and its effects on adjustment to stressful life events. Psychological Bulletin, 136(2), 257-301. https://doi.org/10. 1037/a0018301

Park, C. L., \& Folkman, S. (1997). Meaning in the context of stress and coping. Review of General Psychology, 1, 115-144. https://doi.org/10. 1037/1089-2680.1.2.115

Park, J., \& Baumeister, R. F. (2017). Meaning in life and adjustment to daily stressors. The Journal of Positive Psychology, 12(4), 333-341. https:// doi.org/10.1080/17439760.2016.1209542

Patra, B. N., \& Sarkar, S. (2013). Adjustment disorder: Current diagnostic status. Indian Journal of Psychological Medicine, 35(1), 4-9. https://doi. org/10.4103/0253-7176.112193

Quero, S., Molés, M., Campos, D., Andreu-Mateu, S., Baños, R. M., \& Botella, C. (2019). An adaptive virtual reality system for the treatment of adjustment disorder and complicated grief: 1-year follow-up efficacy data. Clinical Psychology \& Psychotherapy, 26, 204-217. https:// doi.org/10.1002/cpp.2342

Sanz, J., García-Vera, M. P., Espinosa, R., Fortun, M., \& Vazquez, C. (2005). Adaptacion española del Inventario para la depresion de Beck-II (BDIII): Propiedades psicometricas en pacientes con trastornos psicologicos. Clínica Y Salud, 16, 121-142.

Sanz, J., \& Navarro, M. E. (2003). Propiedades psicométricas de una versión española del inventario de ansiedad de Beck (BAI) en estudiantes universitarios. Ansiedad Y estrés, 9(1), 58-84.

Schulenberg, S. E., Strack, K. M., \& Buchanan, E. M. (2011). The meaning in life questionnaire: Psychometric properties with individuals with serious mental illness in an inpatient setting. Journal of Clinical Psychology, 67(12), 1210-1219. https://doi.org/10.1002/jclp.20841

Silver, R. L., Boon, C., \& Stones, M. H. (1983). Searching for meaning in misfortune: Making sense of incest. Journal of Social Issues, 39, 81-102. https://doi.org/10.1111/j.1540-4560.1983.tb00142.x

Steger, M. F. (2012). Making meaning in life. Psychological Inquiry, 23(4), 381-385. https://doi.org/10.1080/1047840X.2012.720832

Steger, M. F., Kashdan, T. B., Sullivan, B. A., \& Lorentz, D. (2008). Understanding the search for meaning in life: Personality, cognitive style, and the dynamic between seeking and experiencing meaning. Journal of Personality, 76(2), 199-228. https://doi.org/10.1111/j.1467-6494. 2007.00484.x
Steger, M. F., Mann, J. R., Michels, P., \& Cooper, T. C. (2009). Meaning in life, anxiety, depression, and general health among smoking cessation patients. Journal of Psychosomatic Research, 67(4), 353-358. https:// doi.org/10.1016/j.jpsychores.2009.02.006

Stevens, J. P. (2007). Intermediate statistics: A modern approach. Mahwah: Lawrence Erlbaum.

Strain, J. J., \& Diefenbacher, A. (2008). The adjustment disorders: The conundrums of the diagnoses. Comprehensive Psychiatry, 49(2), 121-130. https://doi.org/10.1016/j.comppsych.2007.10.002

Szentagotai, A., David, D., Lupu, V., \& Cosman, D. (2008). Rational emotive behavior therapy versus cognitive therapy versus pharmacotherapy in the treatment of major depressive disorder: Mechanisms of change analysis. Psychotherapy: Theory, Research, Practice, Training, 45(4), 523-538. https://doi.org/10.1037/a0014332

Teismann, T., Von Brachel, R., Hanning, S., Grillenberger, M., Hebermehl, L., Hornstein, I., \& Willutzki, U. (2014). A randomized controlled trial on the effectiveness of a rumination-focused group treatment for residual depression. Psychotherapy Research, 24(1), 80-90. https://doi.org/10.1080/10503307.2013.821636

Updegraff, J. A., Silver, R. C., \& Holman, E. A. (2008). Searching for and finding meaning in collective trauma: Results from a national longitudinal study of the 9/11 terrorist attacks. Journal of Personality and Social Psychology, 95, 709-722. https://doi.org/10.1037/0022-3514.95. 3.70

Volkert, J., Schulz, H., Brütt, A. L., \& Andreas, S. (2014). Meaning in life: Relationship to clinical diagnosis and psychotherapy outcome. Journal of Clinical Psychology, 70(6), 528-535. https://doi.org/10.1002/jclp. 22053

Waisberg, J. L., \& Porter, J. E. (1994). Purpose in life and outcome of treatment for alcohol dependence. The British Journal of Clinical Psychology, 33, 49-63. https://doi.org/10.1111/j.2044-8260.1994.tb01093.x

Wong, P. T. P. (1999). Towards an integrative model of meaning-centered counseling and therapy. International Forum of Logotherapy, 22, 47-55.

Zika, S., \& Chamberlain, K. (1992). On the relation between meaning in life and psychological well being. British Journal of Psychology, 83(1), 133-145. https://doi.org/10.1111/j.2044-8295.1992.tb02429.x

How to cite this article: Marco JH, Alonso S, Baños R.

Meaning-making as a mediator of anxiety and depression reduction during cognitive behavioral therapy intervention in participants with adjustment disorders. Clin Psychol Psychother. 2021;28:325-333. https://doi.org/10.1002/cpp.2506 